\title{
COMPARATIVE ANALYSIS OF METAL NANOPARTICLES SYNTHESIZED FROM HIBISCUS ROSA-SINESIS AND THEIR ANTIBACTERIAL ACTIVITY ESTIMATION AGAINST NINE PATHOGENIC BACTERIA
}

\author{
SHRUTI TYAGI ${ }^{1,2 *}$, ARVIND KUMAR ${ }^{2}$, PANKAJ K TYAGI ${ }^{2}$ \\ ${ }^{1}$ Women Scientist Scheme-A (WOS-A), DST, Government of India, India. ${ }^{2}$ Department of Biotechnology, Meerut Institute of Engineering and \\ Technology, Meerut, Uttar Pradesh, India. Email: stgenetics@gmail.com \\ Received: 02 February 2017, Revised and Accepted: 27 February 2017
}

ABSTRACT

Objective: This study demonstrates a simple, cost-effective protocol for biosynthesis of stable silver nanoparticles (AgNPs) and gold nanoparticles (AuNPs) from Hibiscus rosa-sinesis and their comparison by applying antibacterial activities against nine pathogenic bacterial species.

Methods: AgNPs and AuNPs were biosynthesized from H. rosa-sinesis. The antibacterial activities of biosynthesized AgNPs (bio-AgNPs) and biosynthesized AuNPs (bio-AuNPs) were evaluated against 9 pathogenic bacterial species Pseudomonas aeruginosa, Bacillus subtilis, Micrococcus luteus, Staphylococcus aureus, Staphylococcus epidermidis, Enterobacter aerogenes, Escherichia coli, Streptococcus pneumoniae, Aeromonas hydrophila by the agar disc diffusion method.

Results: Biological synthesized AgNP/AuNPs were characterized by an ultraviolet-visible (UV-Vis) spectrophotometer, Fourier transform infrared spectroscopy (FTIR), and transmission electron microscopy (TEM). The existence of silver and gold ions in the extracts was conformed (primary confirmation) through UV-Vis and the maximum plasmon peak was observed at 402 and $530 \mathrm{~nm}$ of bio-AgNPs and bio-AuNPs, respectively. Bio-AgNPs were obtained in 13.01-28.14 nm size range, whereas bio-AuNPs were in 6.32-18.19 nm size range after analysis of TEM images. The results of FTIR spectra indicate that the bio-AuNPs were bound to amine groups and bio-AgNPs to carboxylate ion groups. The antibacterial activities of AgNP/AuNP, the zone of inhibition significantly increased with the increases of concentrations of bio-AgNPs in all pathogenic bacterial species except in the case of S. epidermidis at 50\%, Streptococcus aerogenes and A. hydrophila at 70\%, whereas in the case of bio-AuNPs antibacterial activities were displayed only against B. subtilis at $20 \%$ and $100 \%$ concentration.

Conclusion: This study suggests that AgNPs exhibits outstanding antibacterial activity against pathogenic bacteria as compared to AuNPs synthesized from $H$. rosa-sinensis leaf extract and insights to their potential applicability as an alternative antibacterial agent in microbial and human health system to reduce the resistance ability of pathogenic bacteria.

Keywords: Silver nanoparticles, Gold nanoparticles, Ultraviolet-visible spectroscopy, Fourier transform infrared spectroscopy, Transmission electron microscopyss, Antibacterial activities.

(C) 2017 The Authors. Published by Innovare Academic Sciences Pvt Ltd. This is an open access article under the CC BY license (http://creativecommons. org/licenses/by/4. 0/) DOI: http://dx.doi.org/10.22159/ajpcr.2017.v10i5.17458

\section{INTRODUCTION}

Particles which have two or more dimensions in size range as $1-100 \mathrm{~nm}$ or one billionth part of a meter are defined as one nanoparticles (NPs) [1]. NPs have a unique chemical and physical properties as compared to their solid bulk materials because of their high surface area and electronic properties. Furthermore, these particles have been utilized in many applications, for example, electrochemistry, photochemical, and biomedicine [2]. NPs have many functional platforms that can be utilized for imaging and therapeutic functions. These platforms can be prepared from various inorganic and organic materials, but the inorganic platforms are preferred in therapy and diagnosis because of their easy modification, high drug loading capacity and stability [3]. NPs can be used in drug delivery and in the determination of drugs in pharmaceuticals [4]. Hibiscus is an ornamental plant traditionally used as for anti-inflammatory, demulcent, aphrodisiac, refrigerant, anodyne, laxative, and emollient. The phytochemicals found in this are medicinally important steroids, flavonoids, tannins, reducing sugars, anthocyanin pigment, carotene, thiamine, riboflavin, niacin, and ascorbic acid [5]. It has several medicinal activities such as antitumor, antidiarrheal, antiestrogenic antispermatogenic, androgenic, antiphologistic, antiimplantation, wound healing anticonvulsant [6].

Silver (Ag) is an attractive material for commercialization due to its distinctive properties, such as good conductivity, chemical stability, catalytic activity, and antimicrobial activity [7,8]. AgNPs are utilized in water and air filtration and several medical applications [9]. Although various chemical and biochemical methods are being explored for silver NPs (AgNP) production [10], microbes, plants are also very effective in this process. Various microbes [11-13], plants [14,15], are known to reduce the metals, most of the metallic NPs are spherical $[16,17]$. Extracts from microbes act as both reducing and capping agents in metal NPs synthesis. The reduction of metal ions by combinations of biomolecules found in these extracts such as enzymes or proteins, amino acids, polysaccharides, and vitamins [18] is environmentally benign, yet chemically complex. Gold nanoparticles (AuNPs) are widely used in biotechnology and biomedical field because of their large surface area, and high electron conductivity [19]. The modification of the nanometers is conducted to enhance the interaction of these NPs with biological cells [20]. Drug delivery systems are now utilizing NPs for targeting malignant brain tumors where the conventional therapy is not as much effective due to the enhanced permeability and retention properties of NPs which allow them to accumulate and interact with the tumor cells [21]. The AuNPs has proved to be the safest option for drug delivery due to its low toxicity [22]. NPs such as dendrimers, quantum dots, polymer gels, and AuNPs are widely used in application such as drug delivery systems and imaging [23]. Zinc oxide is widely used in a number of application such as varistors ultraviolet (UV) lasers, gas sensors, photoprinting, electrochemical nanodevice, sunscreen lotion, 
cosmetics, and medicated creams due to its several properties such as good transparency, high electron mobility, and strong room temperature luminescence [24]. Inorganic NPs are widely used as a contrast agent in some application, especially molecular imaging such as computed tomography, positron emission tomography, magnetic resonance imaging, optical imaging, and ultrasound [25,26]. The individual physical, chemical, and photo properties of AuNPs can be utilized innovative ways to control the transport of pharmaceutical compounds and control $[27,28]$. The colloidal $\mathrm{Au}$ is prepared by citrate reduction method [29]. Synthetic AuNPs are of different structure [30] involving $\mathrm{Au}$ nanorods [31,32], spherical structure of Zn NPs [33] silica-Au nanoshells [34] and hollow AuNPs [35]. Noble metallic NPs distinguish themselves from other nanoplatforms such as semiconductor quantum dots, magnetic NPs and polymeric NP by their single surface plasmon resonance, which has a small particle size enhancing all the radiative and irradiative properties of the NPs [36]. Thus, in this paper, we assess the different technologies for synthesis biofabricated NPs as controlled sized $<50 \mathrm{~nm}$ and their efficiency were checked against pathogenic bacterial species. Further, these biofabricated NPs from biological source may be demand for antibiotics in different segments of the antibiotics market, taking the perspectives from industry, clinical practice, and health policy research.

\section{METHODS}

\section{Sample and pathogens collection}

Silver nitrate $\left(\mathrm{AgNO}_{3}\right)$, trisodium citrates, chloroauric acid and nutrient agar of analytical reagent grade were used in this study obtained from Sigma and Merck. Hibiscus rosa-sinesis (Gurhal) leaves used for this study were collected from the garden of Institute campus. The cultures of pathogenic bacteria used to demonstrate the antibacterial activity were collected from the microbiology laboratory of this institute.

\section{Preparation of extracts}

Fresh and green leaves of $H$. rosa sinensis (Gurhal) were collected from the botanical garden of CCS University Meerut. $10 \mathrm{~g}$ leaves were thoroughly washed thrice with double distilled water teared and crushed by using mortar pestle with $10 \mathrm{ml}$ of deionized water. The crushed leaves paste was transferred into a flask containing $90 \mathrm{ml}$ of deionized water to make the volume up to $100 \mathrm{ml}$. This mixture was further boiled for 10 minutes at $80-90^{\circ} \mathrm{C}$. The extract was filtered using Whatman No. 1 filter paper and filtrate was then collected in centrifuged tubes. All centrifuged tubes were centrifuged at 10,000 RPM for 15 minutes at room temperature.

\section{Biological synthesis of AgNPs}

$\mathrm{AgNO}_{3}$ was used as a precursor for synthesis of AgNPs. $10 \mathrm{ml}$ of extract was added to the $90 \mathrm{ml}$ of $1.0 \mathrm{mM}$ aqueous solutions of $\mathrm{AgNO}_{3}$ was added dropwise under continuous stirring at $50^{\circ} \mathrm{C}-60^{\circ} \mathrm{C}$. Conical flask containing the solution was put into a shaker $(150 \mathrm{RPM})$ at $35^{\circ} \mathrm{C}$ for $72 \mathrm{hrs}$. In this process, the extracts act as the reducing and stabilizing agent and change in color indicates the synthesis of AgNPs.

\section{Biological synthesis AuNPs}

AuNPs were obtained by adding $20 \mathrm{ml}$ extract to $20 \mathrm{ml}$ of an aqueous solution of $\mathrm{AuCl}_{4}$, the solution become gray-black after 20 minutes. The production of AgNP, AuNP was monitored by UV-visible (UV-Vis) spectrophotometer. The samples were characterized morphologically by doing transmission electron microscopy (TEM) and scanning electron microscope (SEM).

\section{Characterization of AgNP and AuNP}

Characterization of NPs is significant to evaluate the nature of NPs. The characterization of NPs can be performed by using UV-Vis spectroscopy; TEM and Fourier transform infrared spectroscopy (FTIR). These techniques are used for determining various properties such as the size, shape, and surface area. For example, the morphology shape and particle size of NPs could be specified by TEM and SEM, while UV-Vis spectroscopy technique is used to confirm the formation by showing the plasmon resonance.

\section{UV-Vis spectroscopy}

The colloidal solutions of AgNP and AuNPs from H. rosa sinensis (Gurhal) leaves applied under UV-Vis spectroscopic technique and recorded the plasmon peak. The absorbance spectrum of AgNP and AuNPs was observed at $\sim 400 \mathrm{~nm}$ and $\sim 520 \mathrm{~nm}$, respectively.

\section{TEM}

In the TEM technique, a few prepared AgNP and AuNPs were put on the carbon-coated copper grids. The micrographs of TEM for a drop of NPs are taken by utilizing the TEM instrument operated at an accelerating voltage of for example $200 \mathrm{kV}$. TEM grid is dry. A beam of photons is transmitted through an ultra-thin specimen and interacting with the specimen as it passes through. When the electrons transmitted through the specimen, an image is formed from the interaction. The magnification and focused on the image onto an imaging device [37]. TEM shows the size of AgNP and AuNPs with a different range from and illustrates the morphology image of AuNPs, spherical shape, surface area, and the diameter can be indicated by this technique. TEM of AgNPs can provide the morphology and the distribution of particle size for a profile of the AgNPs.

\section{FTIR analysis}

FTIR analysis of the dried AgNP and AuNPs was carried out through the potassium bromide pellet (FTIR grade) method in 1:100 ratio and spectrum was recorded using Shimadzu to make Fourier trans-form infrared spectrometer at a resolution of $1 / \mathrm{cm}$.

\section{Antibacterial activity}

Antibacterial activities of 9 pathogenic bacterial strains, viz. Pseudomonas aeroginosa, Bacillus subtilis Micrococcus luteus, Staphylococcus epidermidis, Staphylococcus aureus, Enterobacter aerogens, Escherichia coli, Streptococcus pneumoniae, Aeromonas hydrophila species were used for the study. All strains were procured from the microbiology laboratory of the biotechnology department of this institute. The antibacterial activity assays of synthesized AgNPs and AuNP were determined by agar well diffusion method by Tyagi et al. [38]. To test the antibacterial activity of AgNP and AuNP was dissolved in deionized water to make a stock solution. Different concentrations of AgNP and AuNPs were made from the stock solutions $(20 \%, 50 \%, 70 \%$, and $100 \%)$ to determine the antibacterial activity. Antibacterial activities were checked by agar well diffusion method. The plates were left overnight at room temperature to check for any contamination to appear. Overnight grown bacterial cultures of bacterial strains were used as inoculums. Inoculums were prepared in nutrient broth and incubated for $12 \mathrm{hrs}$. Inoculums were spread over fresh nutrient agar plates with a sterile spreader. In a plate 4 wells of 6-8 $\mathrm{mm}$ diameter with $40 \mu \mathrm{l}$ of volume were cut with the help of a sterile cutter. A $40 \mu \mathrm{l}$ solution of different concentrations of AgNP and AuNP was added in the wells to study the antibacterial activity against the used 9 bacterial strains. Plates were incubated for $24 \mathrm{hrs}$ at $37^{\circ} \mathrm{C}$. A clear zone of inhibition around each well was measured with the help of a standard ruler in centimeter. Five replicates of each experiment were done.

\section{RESULTS}

\section{UV-Vis spectra analysis of NPs}

AgNPS

Reduction of $\mathrm{Ag}^{+}$into AgNPs during exposure to the extracts of gurhal plant leaves supernatants is followed by color change. The filtrate treated with $\mathrm{AgNO}_{3}$ and observed the color change from pale yellow to dark brown in comparison to the control solution was depicted (Fig. 1b). Similar changes in color have also been observed in previous studies [39] and hence confirmed the completion of the reaction between all extracts and $\mathrm{AgNO}_{3}$ solution. The color change is the visual method of detection of synthesis of AgNPs. The AgNPs were then characterized using UV-Vis spectroscopy reduction of $\mathrm{Ag}^{+}$was monitored by measuring the UV-Vis range of the reaction mixture at $1 \mathrm{hr}$. The maximum plasmon peak of AgNPs at $402 \mathrm{~nm}$ with absorbance 
0.925 and multiple resonance of three peaks from 384 to $397 \mathrm{~nm}$ were also observed (Fig. 2a).

\section{AuNPs}

Reduction of $\mathrm{Au}^{+}$into AuNPs during exposure to the extracts of gurhal plant leaves is followed by color change. The filtrate treated with chloroauric acid and observed the color change from dark yellow to purple reddish in comparison to the control solution was depicted (Fig. 1a). The color change is the visual method of detection of synthesis of AuNPs. The AuNPs were then characterized by using UV-Vis spectroscopy reduction of $\mathrm{Au}^{+}$ was monitored by measuring the UV-Vis range of the reaction mixture at one $\mathrm{hr}$. The result obtained in this investigation is very interesting in terms of identification of potential plants for synthesizing AuNPs. UV-Vis spectrograph of the colloidal solution of AuNPs has been recorded as a function of time. Absorption spectra of AuNPs formed in the reaction media at 10 minutes have an absorbance peak at $530 \mathrm{~nm}$, broadening of peak indicated that the particles are polydispersed (Fig. $2 \mathrm{~b}$ ).

\section{FTIR analysis of the NPs samples}

AgNPS

FTIR analysis of the freeze-dried sample $H$. rosa sinensis plant leaves extract was carried out to identify the possible interactions between Ag and bioactive molecules, which may be responsible for the synthesis and stabilization (capping material) of AgNPs. The amide linkages between amino acid residues in proteins give rise to well-known indications in the infrared region of the electromagnetic spectrum. FTIR spectrum reveals two peaks at 1236 and 1310,1/cm that correspond to the bending vibrations of the amide group peaks of the proteins, respectively. The amide group peaks corresponding stretching vibrations were seen at 3451 and 3260, 1/cm, respectively (Fig. 3a). The presence of these indications of the peaks of amino acids supports the presence of proteins in cell-free filtrate as observed in UV-Vis spectra. It is well known that protein NPs interactions can occur either
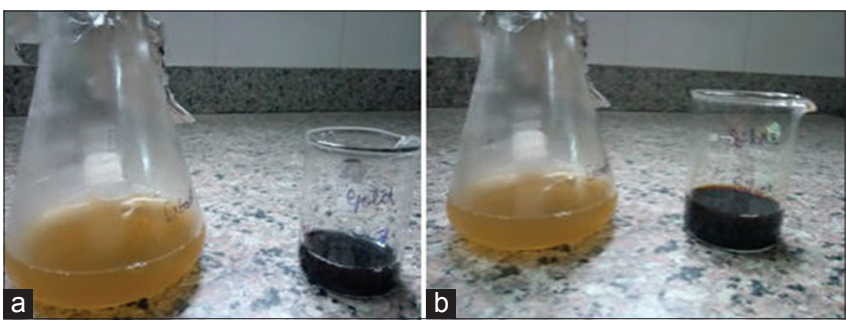

Fig. 1: Process of biological synthesis of nanoparticles from Hibiscus rosa sinensis leaves extracts, the visual method of detection of synthesized nanoparticles. (a) Gold nanoparticles with the color change (b) silver nanoparticles with the color change through free amine groups or cysteine residues in proteins and through the electrostatic attraction of negatively charged carboxylate groups in enzymes [40]. The two peaks observed at 1500 and 1255,1/cm can be assigned to the $\mathrm{C} N$ stretching vibrations of the aromatic and aliphatic amines, respectively [41]. These observations indicate the presence and binding of proteins with AgNPs, which can lead to their possible stabilization. FTIR results revealed that the secondary structure of proteins has not been affected as a consequence of reaction with Ag ions or binding with AgNPs. The finding of FTIR indicates that it is not just the size and shape of proteins, but the conformation of protein molecules that plays an important role in the formation of NPs.

\section{AuNPS}

FTIR analysis of the freeze-dried sample $H$. rosa sinensis plant leaves extract was carried out to identify the possible interaction between the biomolecule and $\mathrm{Au}^{+}$during the biogenic reduction reactions. The band at $3513,1 / \mathrm{cm}$ is assigned for $\mathrm{O}-\mathrm{H}$ stretching vibration of alcohol and phenol compounds and bands observed in 1410,1050 and $1710,1 / \mathrm{cm}$ are due to the $\mathrm{C}-\mathrm{O}$ stretching and $\mathrm{C}=0$ stretching mode of the carbonyl functional groups in alcohol, ethers, acids, and esters. The carbonyl bands at $1710,1 / \mathrm{cm}$ was shifted to $1608,1 / \mathrm{cm}$ during the formation of AuNPs. The shifts in bands at 1710, 1050 and $1410,1 / \mathrm{cm}$ were clearly indicating the coordination of carboxylic acids with AuNPs (Fig. 3b). From the analysis of FTIR studies, it was revealed that the carbonyl group from the amino acid residues and proteins has the stronger ability to bind metal indicating that the proteins could possibly from the metal NPs (i.e., capping of AuNPs) to prevent agglomeration and thereby stabilizing the medium. This suggests that the biological molecules could possibly perform the dual functions of formation and stabilization of AuNPs in the aqueous medium. These results imply that proteins, sugars, and amino acid present in $H$. rosa sinensis plant leaf extract are playing a major role in the reduction of $\mathrm{Au}^{+}$.

\section{TEM analysis of the NPs samples}

AgNPS

TEM images provide further insight into the morphology and particle size, shape, and distribution profile of the AgNPs. H. rosa sinensis plant leaves extract shows some of hexagons, cuboidal and rounded, but mainly spherical shapes NPs were predominant. It is clear that the spherical structures with an average size $18.65 \mathrm{~nm}$ (range of 13.01$28.14 \mathrm{~nm}$ ) and $17.37 \mathrm{~nm}$ at $50 \mathrm{~nm}$ scale with $200 \mathrm{kV}$ accelerating voltage analysis as shown in Fig. 4a-c, respectively. All observed NPs are uniformly distributed without significant agglomeration.

\section{AuNPs}

The resulting AuNPs was analyzed with TEM techniques and conclude that the average mean size of AuNPs was $13.46 \mathrm{~nm}$ (range of 6.32-17.97 nm) at $50 \mathrm{~nm}$ scale (Fig. 5a), whereas an average size $16.00 \mathrm{~nm}$ (range of

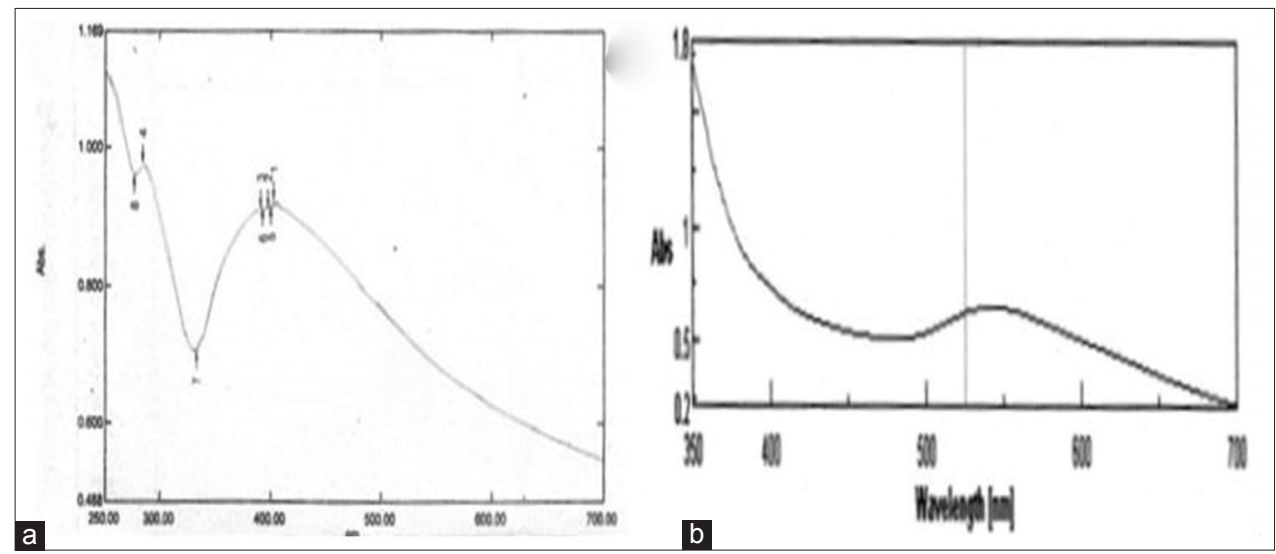

Fig. 2: Ultra violet-visible spectral analysis of biological synthesized nanoparticles from Hibiscus rosa sinensis leaves extracts. (a) silver nanoparticles, (b) gold nanoparticles 


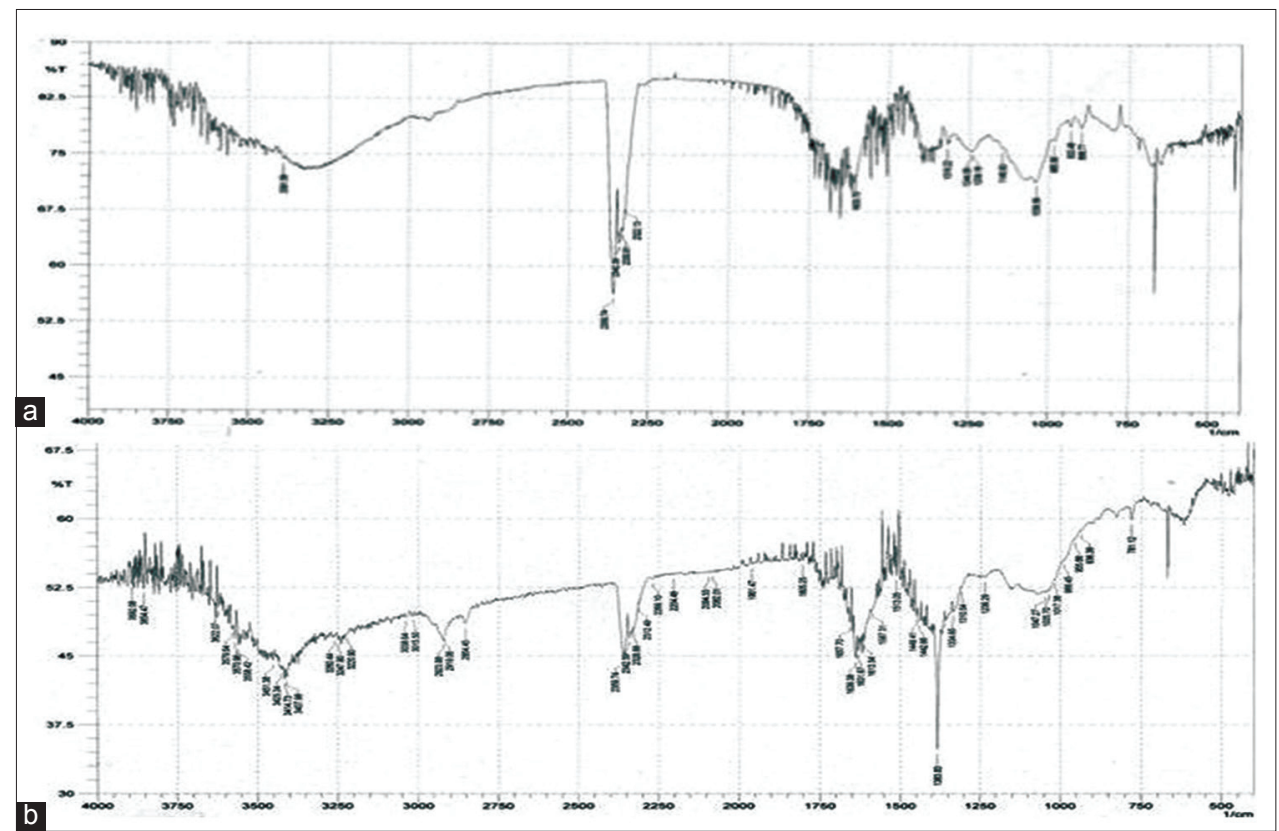

Fig. 3: Fourier transform infrared spectroscopy analysis of biological synthesized nanoparticles from Hibiscus rosa sinensis leaves extracts. (a) silver nanoparticles, (b) gold nanoparticles

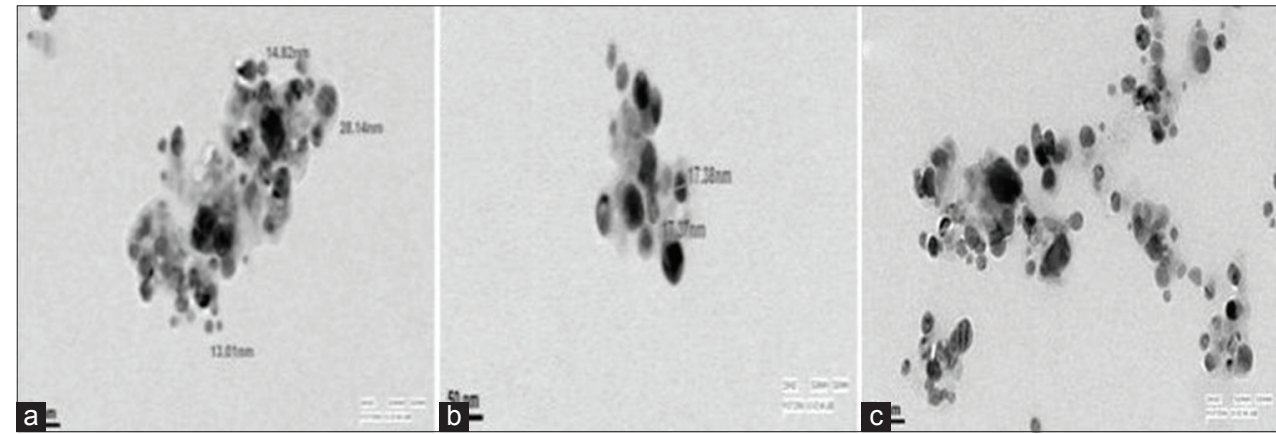

Fig. 4: Transmission electron microscopy (TEM) results analysis of biological synthesized silver nanoparticles from Hibiscus rosa sinensis leaves extracts with showing different sizes and shapes. (a-c) TEM results on $50 \mathrm{~nm}$ scale

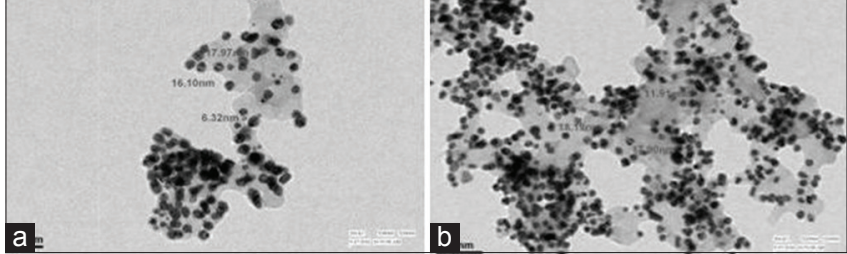

Fig. 5: Transmission electron microscopy (TEM) results analysis of biological synthesized gold nanoparticles from Hibiscus rosa-sinensis leaves extracts with showing different sizes and shapes. (a) TEM results on $50 \mathrm{~nm}$ scale (b) TEM results on $100 \mathrm{~nm}$ scale

11.91-18.19 nm) at $100 \mathrm{~nm}$ scale (Fig. 5b) with $200 \mathrm{kV}$ accelerating voltage analysis which seems to be spherical in morphology. All observed NPs are uniformly distributed without significant agglomeration found uniformly distributed without significant agglomeration.

\section{Antibacterial activity of AgNPs}

Antimicrobial activities of the synthesized AgNPs of H. rosa-sinensis plant leaves extract was determined, using the agar well diffusion method. AgNPs showed inhibition zones ranging from 0.04 to $0.41 \mathrm{~cm}$ against different reference bacterial species. AgNPs showed greater inhibition zone $(0.41 \mathrm{~cm})$ against $E$. coli at $100 \%$ concentration, whereas lesser inhibition zone $(0.04 \mathrm{~cm})$ against $A$. hydrophila at $20 \%$ concentration. All in all, the antibacterial activities of AgNPs showed in an increasing manner of against all pathogenic bacteria in concentrations $(20 \%<50 \%<0 \%<100 \%)$. By comparison, between pathogenic bacterial species against concentrations of AgNPs, the inhibition of the zone was significantly increased while the increases of concentrations of AgNPs except S. epidermidis at 50\%, Streptococcus aerogenes and A. hydrophila at $70 \%$ of all pathogenic bacterial species (Figs. 6 and 7).

\section{Antibacterial activity of AuNPs}

Antimicrobial activities of the synthesized AuNPs of $\mathrm{H}$. rosa-sinensis plant leaves extract was determined, using the disc diffusion method. AuNPs showed inhibition zones ranging from 0.09 to $0.23 \mathrm{~cm}$ against different bacterial species. The maximum and minimum zone of inhibition $0.23 \mathrm{~cm}$ and $0.09 \mathrm{~cm}$ against B. subtilis in $100 \%$ and $20 \%$ concentrations of AuNPs were obtained respectively, whereas the zone of inhibition $0.22 \mathrm{~cm}$ against $P$. aeruginosa was observed in $100 \%$ concentration of AuNPs (Fig. 8). All in all, the antibacterial activities of AuNPs were found only B. subtilis in 2 concentrations (20\% and $100 \%)$ and $P$. aeruginosa in $100 \%$ concentration, rest of 7 pathogenic bacterial species were found in resistance to all 4 concentrations of AuNPs.

\section{DISCUSSION}

Biosynthesis of NPs have received considerable attention due to the fast growing need to develop environmentally benign technologies in 


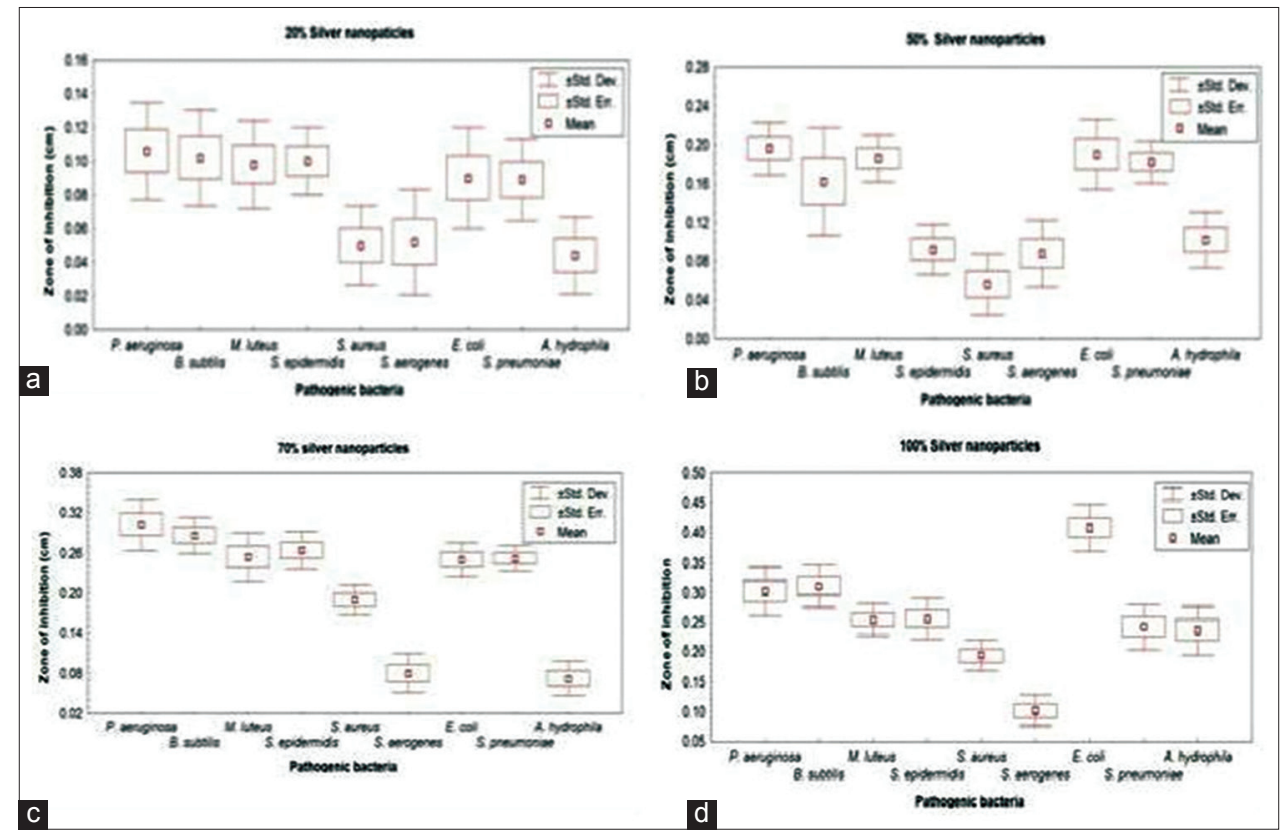

Fig. 6: Graph showing mean, standard deviation, and standard error values of zone of inhibition (cm) of 9 pathogenic bacterial species in silver nanopaticles. (a) $20 \%$ (b) $50 \%$ (c) $70 \%$ and (d) $100 \%$ concentration from Hibiscus rosa-sinensis leaves extracts

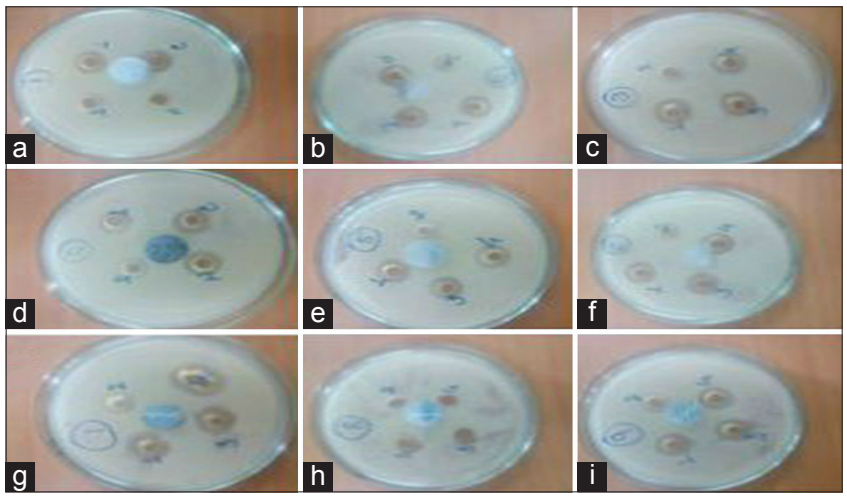

Fig. 7: Antimicrobial activity of silver nanopaticles concentrations $(20 \%, 50 \%, 70 \%, 100 \%)$ against pathogenic bacteria.

(a) Pseudomonas aeruginosa, (b) Bacillus subtilis, (c) Micrococcus luteus, (d) Staphylococcus epidermidis, (e) Staphylococcus aureus, (f) Enterobacter aerogenes, (g) Escherichia coli, (h) Streptococcus pneumoniae, (i) Aeromonas hydrophila by using the agar well diffusion method

nanomaterials synthesis [42]. The phytochemicals derived from plant products serve as a prototype to develop less toxic and more effective medicines for controlling the growth of microorganisms [37,43]. These compounds have significant therapeutic application against human pathogens. Numerous studies have been conducted with the extracts of various plants for screening of antimicrobial activity in search of new antimicrobial compounds [44]. However, there are still limited studies regarding the antibacterial activity of AgNPs from $H$. rosa sinensis plant. The main focus of the present study is that AgNPs reduced the activities of pathogens. We synthesized AgNPs from H. rosa-sinensis, which is easily available, safe, non-toxic and have a variety of medicinal value and phytochemicals that can help in the reduction of metal ions on the other hands, the mechanism considered for the process is plant-assisted reduction due to phytochemicals. The main phytochemicals involved are terpenoids, flavones, ketones, aldehydes, amides, and carboxylic acids. Flavones, organic acids, and quinones are water-soluble phytochemicals that are responsible for the immediate reduction of the metal ions [45]. It was also suggested that the phytochemicals are involved directly in the reduction of the ions and formation of
AgNPs [46]. TEM analysis revealed the size and shape contributed toward the stability of AgNPs [47]. FTIR confirms the presence of different functional groups absorb characteristic frequencies of IR radiations [48]. The interactions of AuNPs play an important role in their properties [49-51]. AuNPs have been commonly utilized in the radiation medicine field as a radiant enhancer [52]. The AuNPs are nontoxic particles with large surface area and can be modified with other molecules, and are used in biomedical fields [53]. The significance of AuNPs in biochemistry field is due to its compatibility, and optical properties. NPs are good therapeutic agents due to their ease transport in the diseased cell and carrier-loading drug [54]. The exact mechanism by which AgNP and AuNPs employ to cause an antimicrobial effect is not clearly known. However, there are various theories suggested about the action of AgNPs on microbes to cause the antimicrobial effect. The AgNPs have ability to anchor to the bacterial cell wall and subsequently penetrate it, thereby causing structural changes in the cell membrane like the permeability of the cell membrane and death of the cell. There is formation of "pits" on the cell surface where the accumulation of the NPs takes place [55]. The formation of free radicals by AgNPs may be considered to be another mechanism by which the cells die [56,57]. It has also been proposed that there can be release of Ag ions by the NPs [58], and these ions can interact with the thiol groups of many vital enzymes and inactivate them [59]. The bacterial cells in contact with Ag absorb Ag ions, which inhibit several functions in the cell and damage the cells. In the recent years, due to the development of resistant strains, antibiotic resistance also has been increased. In this study the selected 9 pathogenic bacteria are causing serious infections and exhibit innate resistance to many antibiotics. These can develop new resistance after exposures to antimicrobial agents. Some antimicrobial agents are extremely irritating and toxic. The studies on drug resistant bacteria in this facet are still limited. Furthermore, AgNPs have gained insight as an excellent antimicrobial agent due to its non-toxic effect on human cells in its low concentration and weaker ability to develop resistance towards Ag ions [60-66]. Similar results were observed in plant extract stabilized NPs may be ideal candidates for future studies exploring their use in biomedical and pharmacy applications, antimicrobial activity [67] and production of metal NPs from biological resources.

\section{CONCLUSION}

This is a simple, cost effective protocol for biosynthesis of AgNP and AuNP from biological materials. This study suggests that AgNPs 


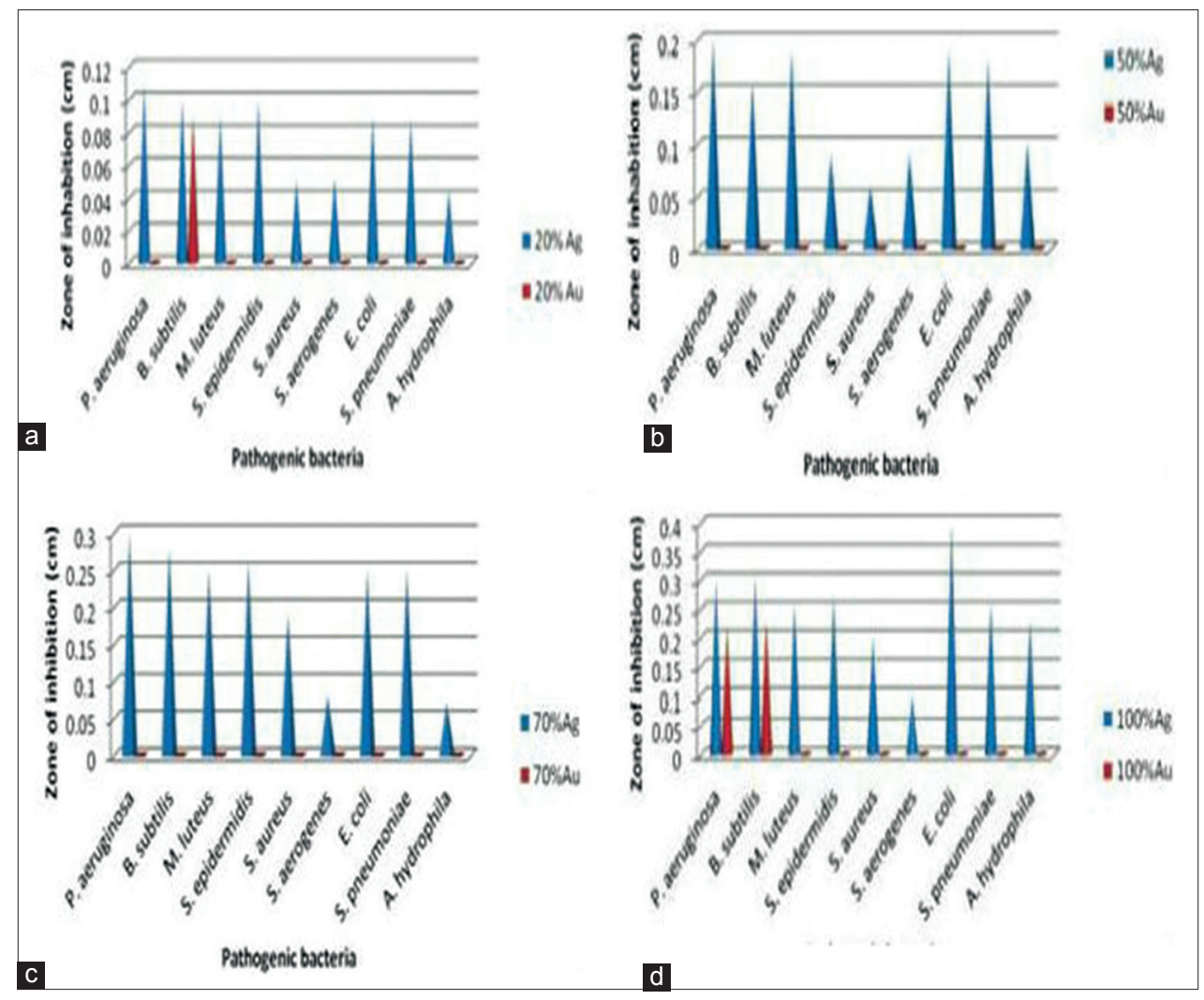

Fig. 8: Comparative analysis of zone of inhibition (cm) and silver/gold nanoparticles against 9 pathogenic bacteria. (a) $20 \%$ concentration, (b) $50 \%$ concentration, (c) $70 \%$ concentration, (d) $100 \%$ concentration

exhibits outstanding antibacterial activity against pathogenic bacteria as compared to AuNPs synthesized from H. rosa sinensis leaf extract and insights to their potential applicability as an alternative antibacterial agent in microbial and human health system to reduce the resistance ability of pathogenic bacteria.

\section{ACKNOWLEDGMENT}

This work was supported in part by a grant from the Department of Science and Technology under the Women Scientist Scheme-A (WOS-A) project no SR/WOS-A/LS-1171/2014 government of India. Authors are highly thankful to Editors/Reviewers of this journal of his/her valuable comments and encouragement for strengthening this manuscript.

\section{REFERENCES}

1. Alanazi FK, Radwan AA, Alsarra IA. Biopharmaceutical applications of nanogold. Saudi Pharm J 2010;18(4):179-93.

2. Di Guglielmo C, López DR, De Lapuente J, Mallafre JM, Suàrez MB. Embryotoxicity of cobalt ferrite and gold nanoparticles: A first in vitro approach. Reprod Toxicol 2010;30(2):271-6.

3. Haruna K, Saleh T, Al Thagfi J, Al-Saadi A. Structural properties, vibrational spectra and surface-enhanced raman scattering of 2,4,6-trichloro and tribromoanilines: A comparative study. J Mol Struct 2016;1121:7-15.

4. Saleh T. Detection: From electrochemistry to spectroscopy with chromatographic techniques, recent trends with nanotechnology. Detection 2014;2(4):27-32.

5. Tyagi S. Role of phytochemicals on biosynthesis of silver nanoparticles from plant extracts and their concentration dependent toxicity impacts on Drosophila melanogaster. Biol Insights 2016;1:21-8.

6. Shivananda Nayak B, Sivachandra Raju S, Orette FA, Chalapathi Rao AV. Effects of Hibiscus rosa sinensis L (Malvaceae) on wound healing activity: A preclinical study in a Sprague Dawley rat. Int J Low Extrem Wounds 2007;6(2):76-81

7. Frattini A, Pellegri N, Nicastro D, Sanctis O. Effect of amine groups in the synthesis of $\mathrm{Ag}$ nanoparticles using aminosilanes. Mater Chem Phys 2005;94(1):148-52.
8. Li P, Li J, Wu C, Wu Q, Li J. Synergistic antibacterial effects of $\beta$-lactam antibiotic combined with silver nanoparticles. Nanotechnology 2005;16(9):1912-7.

9. Alt V, Bechert T, Steinrücke P, Wagener M, Seidel P, Dingeldein E, et al. An in vitro assessment of the antibacterial properties and cytotoxicity of nanoparticulate silver bone cement. Biomaterials 2004;25(18):4383-91.

10. Wiley B, Sun Y, Mayers B, Xia Y. Shape-controlled synthesis of metal nanostructures: The case of silver. Chemistry 2005;11(2):454-63.

11. Panacek A, Kvítek L, Prucek R, Kolar M, Vecerova R, Pizúrova N, et al. Silver colloid nanoparticles: Synthesis, characterization, and their antibacterial activity. J Phys Chem B 2006;110(33):16248-53.

12. Mann S, Frankel R, Blakemore R. Structure, morphology and crystal growth of bacterial magnetite. Nature 1984;310(5976):F405-7.

13. Beveridge TJ, Hughes MN, Lee H, Leung KT, Poole RK, Savvaidis I, et al. Metal-microbe interactions: Contemporary approaches. Adv Microb Physiol 1997;38:177-243.

14. Shankar SS, Rai A, Ahmad A, Sastry M. Rapid synthesis of Au, Ag, and bimetallic Au core-Ag shell nanoparticles using Neem (Azadirachta indica) leaf broth. J Colloid Interface Sci 2004;275(2):496-502.

15. Gardea-Torresdey J, Parsons J, Gomez E, Peralta-Videa J, Troiani H, Santiago $\mathrm{P}$, et al. Formation and growth of Au nanoparticles inside live Alfalfa plants. Nano Lett 2002;2(4):397-401.

16. Chen JC, Lin ZH, Ma XX. Evidence of the production of silver nanoparticles via pretreatment of Phoma sp.3.2883 with silver nitrate. Lett Appl Microbiol 2003;37(2):105-8.

17. Ahmad A, Senapati S, Khan M, Kumar R, Sastry M. Extra, intracellular biosynthesis of gold nanoparticles by an alkalotolerant fungus, Trichothecium spp. J Biomed Nanotechnol 2005;1(1):47-53.

18. Jagadeesh M, Seehra M. Principal magnetic susceptibilities of $\mathrm{MnO}$ and their temperature dependence. Phys Rev B 1981;23(3):1185-9.

19. Tedesco S, Doyle H, Blasco J, Redmond G, Sheehan D. Oxidative stress and toxicity of gold nanoparticles in Mytilus edulis. Aquat Toxicol 2010;100(2):178-86.

20. Mendoza KC, McLane VD, Kim S, Griffin JD. In vitro application of gold nanoprobes in live neurons for phenotypical classification, connectivity assessment, and electrophysiological recording. Brain Res 2010;1325:19-27.

21. Hartono D, Hody, Yang KL, Yung LY. The effect of cholesterol on protein-coated gold nanoparticle binding to liquid crystal-supported 
models of cell membranes. Biomaterials 2010;31(11):3008-15.

22. Lukianova-Hleb EY, Wagner DS, Brenner MK, Lapotko DO. Cellspecific transmembrane injection of molecular cargo with gold nanoparticle-generated transient plasmonic nanobubbles. Biomaterials 2012;33(21):5441-50.

23. Mishra A, Tripathy S, Yun S. Fungus mediated synthesis of gold nanoparticles and their conjugation with genomic DNA isolated from Escherichia coli and Staphylococcus aureus. Process Biochem 2012;47(5):701-11

24. Etame AB, Smith CA, Chan WC, Rutka JT. Design and potential application of PEGylated gold nanoparticles with size-dependent permeation through brain microvasculature. Nanomedicine 2011;7(6):992-1000

25. Chen PC, Mwakwari SC, Oyelere AK. Gold nanoparticles: From nanomedicine to nanosensing. Nanotechnol Sci Appl 2008;1:45-65.

26. Sershen SR, Westcott SL, Halas NJ, West JL. Temperature-sensitive polymer-nanoshell composites for photothermally modulated drug delivery. J Biomed Mater Res 2000;51(3):293-8.

27. Pissuwan D, Valenzuela SM, Cortie MB. Therapeutic possibilities of plasmonically heated gold nanoparticles. Trends Biotechnol 2006;24(2):62-7.

28. Saleh T. Sensing of chlorpheniramine in pharmaceutical applications by sequential injector coupled with potentiometer. J Pharm Anal 2011;1(4):246-50

29. Idris AM, Ibrahim AE, Abulkibash AM, Saleh TA, Ibrahim KE. Rapid inexpensive assay method for verapamil by spectrophotometric sequential injection analysis. Drug Test Anal 2011;3(6):380-6.

30. Turkevich J, Garton G, Stevenson P. The color of colloidal gold. J Colloid Sci 1954;9:26-35.

31. Ying Y, Chang SS, Lee CL, Wang CC. Gold nanorods: Electrochemical synthesis and optical properties. J Phys Chem B 1997;101(34):6661-4.

32. Murphy CJ, Sau TK, Gole AM, Orendorff CJ, Gao J, Gou L, et al. Anisotropic metal nanoparticles: Synthesis, assembly, and optical applications. J Phys Chem B 2005;109(29):13857-70.

33. Mishra M, Khan N, Sirohi S. Chemical synthesis and characterization of zinc nanoparticles and its antibacterial effect against pathogenic bacteria. Nanobiotechnology 2016;1:13-20.

34. Oldenburg S, Averitt R, Westcott S, Halas N. Nanoengineering of optical resonances. Chem Phys Lett 1998;288(2-4):243-7.

35. Sun Y, Mayers B, Xia Y. Template-engaged replacement reaction: A one-step approach to the large-scale synthesis of metal nanostructures with hollow interiors. Nano Lett 2002;2(5):481-5.

36. Link S, El-Sayed M. Spectral properties and relaxation dynamics of surface plasmon electronic oscillations in gold and silver nanodots and nanorods. J Phys Chem B 1999;103(40):8410-26.

37. Tripathi A, Sirohi R. Antimicrobial activities of silver nanoparticles synthesized from peel of fruits and vegetables. Biol Insights 2016;1:29-34.

38. Tyagi P, Tyagi S, Verma C, Rajpal A. Estimation of toxic effects of chemically and biologically synthesized silver nanoparticles on human gut microflora containing Bacillus subtilis. J Toxicol Environ Health Sci 2013;5(9):172-7.

39. Saini J, Kashyap D, Batra B, Kumar S, Kumar R, Malik D. Green synthesis of silver nanoparticles by using Neem (Azadirachta indica) and Amla (Phyllanthus emblica) leaf extract. Indian J Appl Res 2011;3(5):209-10

40. Alt V, Bechert T, Steinrücke P, Wagener M, Seidel P, Dingeldein E, et al. In vitro testing of antimicrobial activity of bone cement. Antimicrob Agents Chemother 2004;48(11):4084-8.

41. Morley K, Webb P, Tokareva N, Krasnov A, Popov V, Zhang J. Synthesis and characterisation of advanced UHMWPE/silver nanocomposites for biomedical applications. Eur Polym J 2007;43(2):307-14.

42. Paul D, Sinha S. Extracellular synthesis of silver nanoparticles using Pseudomonas aeruginosa KUPSB12 and its antibacterial activity. Jordan J Biol Sci 2014;7(4):245-50

43. Ahmad I, Beg AZ. Antimicrobial and phytochemical studies on 45 Indian medicinal plants against multi-drug resistant human pathogens. J Ethnopharmacol 2001;74(2):113-23.

44. Prabhu S, Poulose E. Silver nanoparticles: Mechanism of antimicrobial action, synthesis, medical applications, and toxicity effects. Int Nano Lett 2012;2(1):32

45. Jha AK, Prasad K, Prasad K, Kulkarni AR. Plant system: Nature's nanofactory. Colloids Surf B Biointerfaces 2009;73(2):219-23.

46. Tyagi PK, Mishra M, Khan N, Tyagi S, Sirohi S. Toxicological study of silver nanoparticles on gut microbial community probiotic. Environ Nanotechnol Monit Manage 2016;5:36-43.

47. Tyagi PK. Production of metal nanoparticles from biological resources. Int J Curr Microbiol Appl Sci 2016;5(3):548-58.

48. Bunghez I, Patrascu M, Badea N, Doncea S, Popescu A, Ion R. Antioxidant silver nanoparticles green synthesized using ornamental plants. J Optoelectron Adv Mater 2012;14(11-12):1016-22.

49. Kalainila P, Subha V, Ravindran R, Sahadevan R. Synthesis and characterization of silver nanoparticles from Erythrina indicia. Asian J Pharm Clin Res 2014;7(2):39-43.

50. Müller-Goymann CH. Solid lipid nanoparticles for drug delivery. J Drug Deliv Sci Technol 2011;21(1):89-99.

51. Joshi SA. Solid lipid nanoparticle: A review. IOSR J Pharm 2012;2(6):34-44

52. Deb S, Patra HK, Lahiri P, Dasgupta AK, Chakrabarti K, Chaudhuri U. Multistability in platelets and their response to gold nanoparticles. Nanomedicine 2011;7(4):376-84.

53. Ganeshkumar M, Sastry T, Kumar MS, Dinesh MG, Kannappan S, Suguna L. Sun light mediated synthesis of gold nanoparticles as carrier for 6-mercaptopurine: Preparation, characterization and toxicity studies in zebrafish embryo model. Mater Res Bull 2012;47(9):2113-9.

54. Guo Q, Guo Q, Yuan J, Zeng J. Biosynthesis of gold nanoparticles using a kind of flavonol: Dihydromyricetin. Colloids Surfaces A Physicochem Eng Asp 2014;441:127-32.

55. Lan MY, Hsu YB, Hsu CH, Ho CY, Lin JC, Lee SW. Induction of apoptosis by high-dose gold nanoparticles in nasopharyngeal carcinoma cells. Auris Nasus Larynx 2013;40(6):563-8.

56. Sondi I, Salopek-Sondi B. Silver nanoparticles as antimicrobial agent: A case study on E. coli as a model for Gram-negative bacteria. J Colloid Interface Sci 2004;275(1):177-82.

57. Danilczuk M, Lund A, Sadlo J, Yamada H, Michalik J. Conduction electron spin resonance of small silver particles. Spectrochim Acta A Mol Biomol Spectrosc 2006;63(1):189-91.

58. Kim J, Kuk E, Yu K, Kim J, Park S, Lee H, et al. Antimicrobial effects of silver nanoparticles. Nanomed Nanotechnol Biol Med 2007;3(1):95-101.

59. Feng QL, Wu J, Chen GQ, Cui FZ, Kim TN, Kim JO. A mechanistic study of the antibacterial effect of silver ions on Escherichia coli and Staphylococcus aureus. J Biomed Mater Res 2000;52(4):662-8.

60. Matsumura Y, Yoshikata K, Kunisaki S, Tsuchido T. Mode of bactericidal action of silver zeolite and its comparison with that of silver nitrate. Appl Environ Microbiol 2003;69(7):4278-81.

61. Shahverdi AR, Fakhimi A, Shahverdi HR, Minaian S. Synthesis and effect of silver nanoparticles on the antibacterial activity of different antibiotics against Staphylococcus aureus and Escherichia coli. Nanomedicine 2007;3(2):168-71

62. Pal S, Tak YK, Song JM. Does the antibacterial activity of silver nanoparticles depend on the shape of the nanoparticle? A study of the Gram-negative bacterium Escherichia coli. Appl Environ Microbiol 2007;73(6):1712-20

63. Sharma VK, Yngard RA, Lin Y. Silver nanoparticles: Green synthesis and their antimicrobial activities. Adv Colloid Interface Sci 2009; 145(1-2):83-96.

64. Kumar N, Das S, Jyoti A, Kaushik S. Synergistic effect of silver nanoparticles with doxycycline against Klebsiella pneumonia. Int $\mathrm{J}$ Pharm Pharm Sci 2016;8(7):183-6.

65. Rao M, Savithramma N. Antibacterial activity of biologically synthesis silver nanoparticles from leaf extract of Alangium salvifolium (L.F) wang. Int J Pharm Pharm Sci 2014;6(8):375-8.

66. Tripathi GD, Javed Z. Screening for synthesis of silver nanoparticles from red ripened capsicum. Biol Insights 2016;1:43-6.

67. Tyagi PK, Mishra M, Khan N, Tyagi S, Sharma H, Sirohi S. Antibacterial activity and toxicological evaluation of sliver nanoparticles through toxtrak toxicity test. Int J Curr Microbiol Appl Sci 2015;4(3):1043-55. 